\title{
Efficacy of OK-432 Therapy for the Incisionless Treatment of Head and Neck Cystic Masses
} Case series

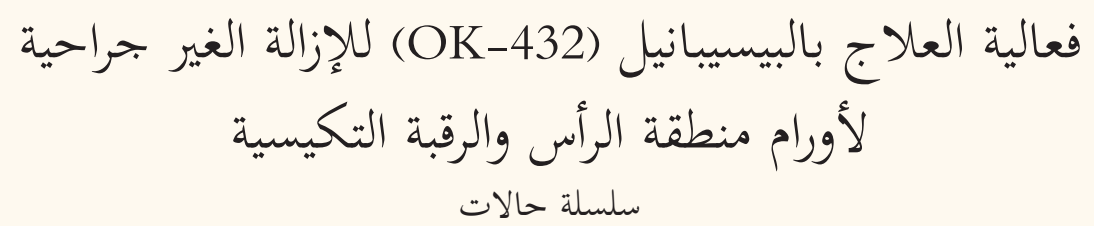

$$
\text { هشام يوسف علي حسن و محمد عامر رضوان }
$$

ABSTRACT: Head and neck masses can present in different pathologies that usually vary according to the age of the patient. We report five cases of benign head or neck masses occurring among patients of different ages who were managed at the Bahrain Defence Force Royal Medical Services Hospital, Ar-Rifaa, Bahrain, between 2005-2014. All of the patients were treated using the sclerotherapeutic agent OK-432. Although surgical removal is usually considered optimal treatment in the management of such cases, OK-432 appears to be a promising alternative.

Keywords: Sclerotherapy; OK-432; Lymphatic Abnormalities; Branchial Cyst; Thyroglossal Cyst; Cystic Hygroma; Case Series; Bahrain.

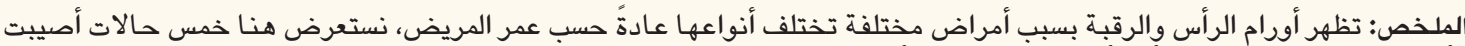

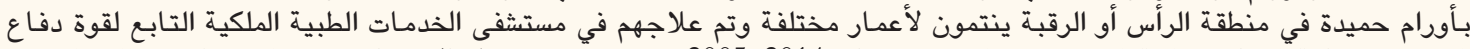

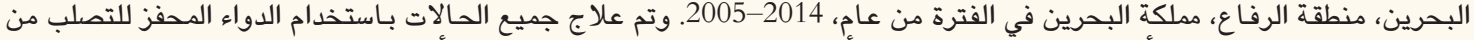

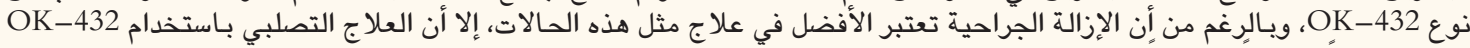

$$
\begin{aligned}
& \text { قد يوفر بديلاً مناسباً وناجحاً. } \\
& \text { الكلمات المفتاحية: العلاج التصلبي؛ OK-432؛ عيوب الجهاز اللمفاوي؛ التكيس الخيشومي؛ التكيس الدرقي اللساني؛ الورم المائي الكيسي؛ } \\
& \text { سلسلة حالات؛ البحرين. }
\end{aligned}
$$

A MIXTURE OF BACTERIA IN A HEATattenuated form was first used to treat inoperable malignancies in 1891 . $^{1}$ Subsequently, in 1967, a Streptococcus pyogenes strain was found to have a positive anticancer effect. ${ }^{2}$ These experiments led to the development of OK-432, a freezedried product prepared from the Su strain of the group A Streptococcus pyogenes species. Upon exposure to benzylpenicillin and heat treatment, the toxinproducing capacity of the bacterium is eliminated and its anticancer properties are enhanced. ${ }^{3}$ This process involves heating the Su strain in the presence of benzylpenicillin at $37{ }^{\circ} \mathrm{C}$ for 20 minutes and then $45{ }^{\circ} \mathrm{C}$ for 30 minutes. At this stage, the product is known as PC-B-45 or OK-431, before becoming OK-432 after being freeze-dried. ${ }^{3}$ The product contains an intact bacterial cell wall devoid of its toxin-producing properties, consequently eliminating its ability to cause infection and proliferate. Each dose is measured in Klinische Einheit (KE), of which one KE equals $0.1 \mathrm{mg}$ of freeze-dried Streptococci containing approximately $1 \times 10^{8}$ cells. $^{3}$

Cystic neck masses can be either congenital or acquired. Branchial cleft cysts, thyroglossal duct cysts, cystic lymphangiomas, dermoid cysts, ranulae and laryngoceles are common congenital neck masses, while acquired neck cysts include laryngoceles, cystic schwannomas and parotid cysts. ${ }^{4}$ A provisional diagnosis can be made based on the age and clinical presentation of the patient, which can subsequently be confirmed using radiological and pathological investigations. In general, benign cystic neck masses such as branchial cleft cysts, lymphangiomas and plunging ranulae are usually amenable to surgical excision; however, the lesions may recur due to the technicallychallenging nature of the surgical intervention or inadequate excision to avoid nerve or vessel injury. ${ }^{5}$ Classically, residual disease and subsequent recurrence is more commonly encountered with lymphatic malformations and branchial cystic masses. ${ }^{6}$ 
Alternative non-surgical modalities-including cryotherapy, diathermy, radiofrequency ablation and laser treatment-have been employed in the treatment of cystic head and neck lesions, with varying degrees of success. ${ }^{7}$ A more appealing alternative is sclerotherapy, including bleomycin, ethanol and sodium tetradecyl sulphate. ${ }^{8}$ In 1986, Ogita et al. first noted that OK-432 injections were effective in reducing or even completely resolving unresectable paediatric lymphangiomas. ${ }^{9}$ Since then, OK-432 has been investigated to determine its potential benefits in treating head and neck cystic masses in both children and adults. ${ }^{10}$ Patients who fail to respond to surgical management are often successfully treated with OK-432, with even more promising results in conjunction with surgery. ${ }^{11}$ Overall, OK-432 has proven effective in the treatment of malignant ascites, pleural effusion and lymphatic malformations. ${ }^{12}$ This case series describes five patients with cystic head or neck lesions who were successfully treated with OK-432 therapy at the Bahrain Defence Force Royal Medical Services Hospital, Ar-Rifaa, Bahrain.

\section{Case One}

A 54-year-old woman presented in 2014 with a recurrent branchial cyst following a previous surgical excision at another hospital. Postoperatively, she had suffered from temporary palsy of the marginal mandibular branch. At presentation, the cyst measured $3.9 \mathrm{x}$ $1.5 \mathrm{~cm}$ and was located in the left lateral region of the upper neck [Figure 1]. The patient feared undergoing a second, potentially more difficult surgery with an increased risk of complications. For this reason, intralesional OK-432 treatment was initiated. After two sessions, the cyst had regressed and was no longer visible or palpable. The patient experienced no complications. She was followed up for two years after the treatment, with no evidence of recurrence. Unfortunately, longer-term follow-up was not possible as the patient moved abroad.

\section{Case Two}

A two-year-old male child presented in 2012 with a three-month history of a cyst in the left upper neck, measuring $5.2 \times 3.5 \mathrm{~cm}$ [Figure 2]. The patient underwent nine sessions of OK-432 sclerotherapy, with no complications, resulting in complete resolution of the lesion. The patient was followed up for four years with no evidence of recurrence.
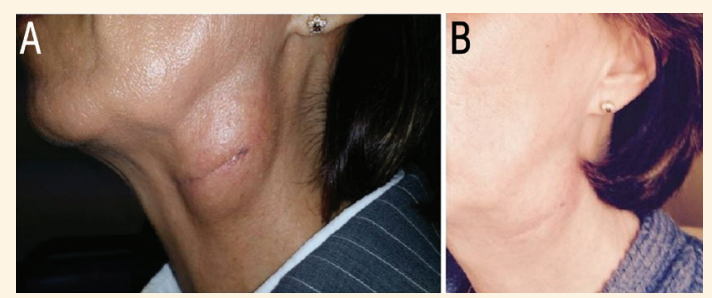

Figure 1: Photographs of a 54-year-old woman with a left branchial cyst which had (A) recurred following surgery but (B) resolved following OK-432 treatment.
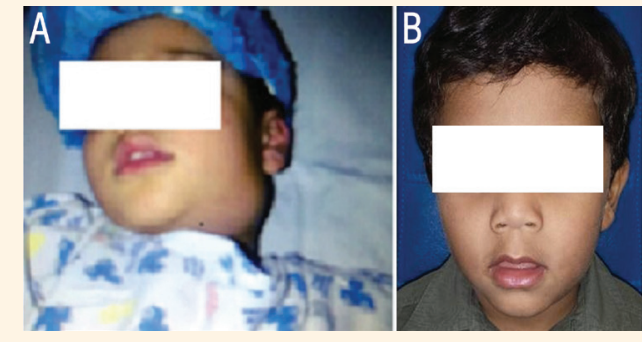

Figure 2: Photographs of a two-year-old male child with a left branchial cyst (A) before and (B) after treatment with OK-432 sclerotherapy.

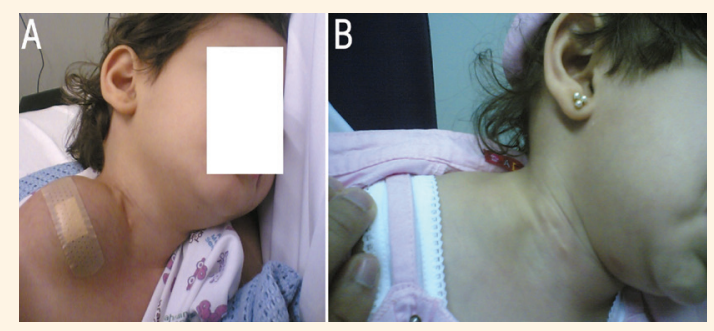

Figure 3: Photographs of an eight-month-old female child with a cystic hygroma (A) before and (B) after treatment with OK-432 sclerotherapy.

\section{Case Three}

An eight-month-old female child presented in 2005 with a congenital mass measuring $6.21 \times 4.52 \times 3.92 \mathrm{~cm}$ in the right supraclavicular fossa [Figure 3]. Clinically and radiologically, the mass appeared consistent with a cystic hygroma. Three sessions of OK-432 sclerotherapy resulted in the total dissolution of the cyst. The patient had no complications and was followed up for nine years with no recurrence.

\section{Case Four}

A 30-year-old woman presented in 2011 with a fivemonth history of a midline neck swelling that moved upon swallowing or extension of the tongue. Computed tomography of the neck showed a cystic mass measuring $2.5 \times 1.5 \times 2.7 \mathrm{~cm}$, consistent with a thyroglossal cyst. 
Table 1: Summary of five cases of benign cystic head or neck masses treated with OK-432 sclerotherapy

\begin{tabular}{|c|c|c|c|c|c|}
\hline Case & Diagnosis & Age in years & Size in $\mathbf{c m}$ & $\begin{array}{c}\text { Number of } \\
\text { treatment sessions }\end{array}$ & Outcome \\
\hline 1 & Branchial cyst & 54 & $3.9 \times 1.5$ & 2 & Resolved \\
\hline 2 & Branchial cyst & 2 & $5.2 \times 3.5$ & 9 & Resolved \\
\hline 3 & Cystic hygroma & 0.6 & $6.21 \times 4.52 \times 3.92$ & 3 & Resolved \\
\hline 5 & Benign parotid cyst & 44 & $6.0 \times 1.4$ & 1 & Resolved \\
\hline
\end{tabular}

As the patient did not wish to undergo a surgery which might potentially cause scarring, OK-432 treatment was her preferred option. She completed a total of four sessions of OK-432 sclerotherapy uneventfully, with no subsequent recurrence over the next three years.

\section{Case Five}

A 44-year-old man presented in 2013 with a left parotid cystic swelling that had persisted for a year. Ultrasound-guided fine needle aspiration cytology confirmed the benign nature of the cystic mass, with a final diagnosis of an idiopathic benign cyst. The patient was given a single dose of intralesional OK-432 under ultrasound guidance and the swelling resolved completely without any complications.

None of the five patients demonstrated any allergic reactions to the treatment or untoward side-effects. In addition, all of the patients were compliant with the planned treatment and participated in each session as scheduled. A summary of the cases is provided in Table 1.

\section{Discussion}

Overall, the outcome of OK-432 treatment for all five patients reported in the current case series was positive, with no undue adverse reactions observed. Several previous reports have indicated the effectiveness of OK-432 sclerotherapy as treatment for a variety of cystic neck lesions, usually resulting in total or near complete resolution of the lesion with no recurrence. ${ }^{10-12}$ In their original research, Ogita et al. reported an overall cure rate of 91.3\%. In the current case series, all five of the patients were cured as a result of OK-432 sclerotherapy; moreover, the treatment was able to resolve the postoperative recurrence of a branchial cyst in case one. Differences in the patients' ages at the time of treatment did not seem to affect the efficacy of the treatment. Additionally, none of the patients reported any skin discoloration or local scarring during or after OK-432 treatment. This is consistent with the findings of Ohta et al. ${ }^{13}$
During embryological development, the failed closure of the branchial cleft can lead to the formation of either a branchial cyst (75\%) or a sinus fistula (25\%). ${ }^{14}$ In the current case series, two patients (cases one and two) had unilocular branchial cysts. Interestingly, the first case involved an adult who had previously undergone surgical excision and subsequent recurrence of the lesion. Neither cases had residual masses after treatment, yielding a $100 \%$ response rate to OK-432 sclerotherapy alone. Kim et al. reported that $60.8 \%$ of patients with unilocular branchial cysts experienced total regression following OK-432 treatment, with no or partial response in cases of multilocular cysts. ${ }^{7}$ In another study, Roh et al. found that seven out of 12 patients with branchial cysts experienced full resolution following OK-432 treatment, while three patients exhibited a partial response and the treatment failed in two patients. ${ }^{15}$ In both of the aforementioned studies, patients who did not respond to OK-432 treatment subsequently underwent surgical excision, thus indicating that this may be a potential salvage option in such cases. ${ }^{7,15}$

Lymphatic malformations are classified into microcystic, macrocystic and combined types. In $50 \%$ of cases, the malformations are present at birth, with another $40 \%$ emerging by the age of two years. ${ }^{16}$ The spontaneous resolution of cystic hygromas is rare and occurs in less than $12.5 \%$ of cases. ${ }^{17}$ Surgical management is complicated by the high risk of injury to the surrounding neurovascular structures, scarring and recurrence. Various sclerotherapy agents have been used to treat macrocystic lymphatic malformations, including alcoholic solution of zein, pure ethanol, bleomycin A5, doxycycline, acetic acid and polidocanol. ${ }^{18}$ In the third case reported in the present series, the patient responded well to OK-432 therapy with no residual mass or recurrence of the cystic hygroma after three doses. In their study of massive macrocystic lymphatic malformations, Chen et al. observed excellent outcomes with a combination of fibrin glue, OK-432 and bleomycin in 53\% of patients, in comparison to good and partial outcomes in 33\% and $13 \%$ of cases, respectively. ${ }^{19}$ None of the patients required surgical excision. ${ }^{19}$ 
Thyroglossal duct cysts account for $70 \%$ of congenital neck masses; these lesions have a bimodal age distribution in which $90 \%$ of patients present by the age of 10 years, with a second peak in young adulthood. ${ }^{4}$ Surgery in the form of a classic Sistrunk procedure is the preferred method of management. ${ }^{20}$ Kim et al. reported reduction in the volume of the cyst in $81.3 \%$ of patients undergoing ethanol sclerotherapy ablation..$^{21}$ The same authors reported that $41.4 \%$ of thyroglossal duct cysts treated with OK-432 showed complete regression. ${ }^{22}$ Ohta et al. reported that OK-432 therapy had better results for patients with thyroglossal cysts compared to branchial cysts. ${ }^{23}$ However, in the current case series, there was complete regression in both cases one and four, regardless of the type of cyst.

Cystic lesions in the parotid gland can be either bilateral or unilateral and congenital or acquired. Congenital cysts can present at birth but most often reveal themselves in adulthood. ${ }^{4}$ Occasionally, systemic diseases such as Sjögren's syndrome and HIV may present with bilateral benign parotid cysts. ${ }^{24}$ While benign parotid cysts are usually managed surgically, there has been recent evidence supporting the use of sclerotherapy. For example, Monama et al. reported the complete resolution of parotid cysts without morbidity in three adult patients following bleomycin sclerotherapy. ${ }^{25}$ In the current case series, the fifth patient underwent aspiration of a parotid cyst under ultrasonic guidance in order to exclude malignancy before commencing OK-432 treatment. This resulted in complete regression with no recurrence within the subsequent follow-up period.

\section{Conclusion}

Sclerotherapy is the optimal therapeutic choice for a variety of benign cystic neck masses. The safety, effectiveness and economic and cosmetic advantages of the sclerotherapeutic agent OK-432 make this modality a favourable alternative to surgery in the management of various otolaryngological cystic head and neck masses, including lymphatic cystic lesions as well as thyroglossal duct and branchial cysts. Furthermore, surgery can be reserved as a salvage procedure following OK-432 treatment in cases of postsurgical recurrence or residual disease.

\section{References}

1. Wiemann B, Starnes CO. Coley's toxins, tumor necrosis factor and cancer research: A historical perspective. Pharmacol Ther 1994; 64:529-64. doi: 10.1016/0163-7258(94)90023-X.
2. Okamoto H, Shoin S, Koshimura S, Shimizu R. Studies on the anticancer and streptolysin S-forming abilities of hemolytic streptococci. Jpn J Microbiol 1967; 11:323-36. doi: 10.1111/ j.1348-0421.1967.tb00350.x.

3. Okamoto H, Shoin S, Koshimura S. Streptolysin S-forming and antitumor activities of group A streptococci. In: Jeljaszewicz J, Wadstrom T, Eds. Bacterial Toxins and Cell Membranes. New York, USA: Academic Press Inc., 1978. P. 259.

4. Mittal MK, Malik A, Sureka B, Thukral BB. Cystic masses of neck: A pictorial review. Indian J Radiol Imaging 2012; 22:334-43. doi: 10.4103/0971-3026.111488.

5. Bloom DC, Perkins JA, Manning SC. Management of lymphatic malformations. Curr Opin Otolaryngol Head Neck Surg 2004; 12:500-4. doi: 10.1097/01.moo.0000143971.19992.2d.

6. Kim KH, Sung MW, Roh JL, Han MH. Sclerotherapy for congenital lesions in the head and neck. Otolaryngol Head Neck Surg 2004; 131:307-16. doi: 10.1016/j.otohns.2004.02.018.

7. Kim MG, Lee NH, Ban JH, Lee KC, Jin SM, Lee SH. Sclerotherapy of branchial cleft cysts using OK-432. Otolaryngol Head Neck Surg 2009; 141:329-34. doi: 10.1016/j.otohns.2009.05.022.

8. Bajpai H, Bajpai S. Comparative analysis of intralesional sclerotherapy with sodium tetradecyl sulfate versus bleomycin in the management of low flow craniofacial soft tissue vascular lesions. J Maxillofac Oral Surg 2012; 11:13-20. doi: 10.1007/ s12663-011-0325-7.

9. Ogita S, Tsuto T, Deguchi E, Tokiwa K, Nagashima M, Iwai N OK-432 therapy for unresectable lymphangiomas in children. J Pediatr Surg. 1991; 26:263-8. doi: 10.1016/0022-3468(91)90500-S.

10. Smith MC, Zimmerman MB, Burke DK, Bauman NM, Sato Y, Smith RJ, et al. Efficacy and safety of OK-432 immunotherapy of lymphatic malformations. Laryngoscope 2009; 119:107-15. doi: 10.1002/lary.20041.

11. Kim SY, Lee S, Seo JM, Lim SY. Postoperative adjuvant OK432 sclerotherapy for treatment of cervicofacial lymphatic malformations: An outcomes comparison. Int J Pediatr Otorhinolaryngol 2015; 79:570-5. doi: 10.1016/j.ijporl.2015.01.030.

12. Kitsuki H, Katano M, Ikubo A, Morisaki T, Annan K, Tanaka M, et al. Induction of inflammatory cytokines in effusion cavity by OK-432 injection therapy for patients with malignant effusion: Role of interferon-gamma in enhancement of surface expression of ICAM-1 on tumor cells in vivo. Clin Immunol Immunopathol 1996; 78:283-90. doi: 10.1006/clin.1996.0040.

13. Ohta N, Fukase S, Watanabe T, Ito T, Aoyagi M. Effects and mechanism of OK-432 therapy in various neck cystic lesions. Acta Otolaryngol 2010; 130:1287-92. doi: 10.3109/ 00016489.2010.483480

14. Deane SA, Telander RL. Surgery for thyroglossal duct and branchial cleft anomalies. Am J Surg 1978; 136:348-53. doi: 10.1016/0002-9610(78)90292-1.

15. Roh JL, Sung MW, Hyun Kim K, Il Park C. Treatment of branchial cleft cyst with intracystic injection of OK-432. Acta Otolaryngol 2006; 126:510-4. doi: 10.1080/00016480500437443.

16. Mulligan PR, Prajapati HJ, Martin LG, Patel TH. Vascular anomalies: Classification, imaging characteristics and implications for interventional radiology treatment approaches. Br J Radiol 2014; 87:20130392. doi: 10.1259/bjr.20130392.

17. Kennedy TL. Cystic hygroma-lymphangioma: A rare and still unclear entity. Laryngoscope 1989; 99:1-10. doi: 10.1288/0000 5537-198910001-00001.

18. Farnoosh S, Don D, Koempel J, Panossian A, Anselmo D, Stanley P. Efficacy of doxycycline and sodium tetradecyl sulfate sclerotherapy in pediatric head and neck lymphatic malformations. Int J Pediatr Otorhinolaryngol 2015; 79:883-7. doi: 10.1016/j.ijporl.2015.03.024. 
19. Chen WL, Huang ZQ, Chai Q, Zhang DM, Wang YY, Wang HJ, et al. Percutaneous sclerotherapy of massive macrocystic lymphatic malformations of the face and neck using fibrin glue with OK-432 and bleomycin. Int J Oral Maxillofac Surg 2011; 40:572-6. doi: 10.1016/j.ijom.2011.01.009.

20. Al-Thani H, El-Menyar A, Sulaiti MA, El-Mabrok J, Hajaji K, Elgohary $\mathrm{H}$, et al. Presentation, management, and outcome of thyroglossal duct cysts in adult and pediatric populations: A 14-year single center experience. Oman Med J 2016; 31:276-83. doi: $10.5001 /$ omj.2016.54.

21. Kim SM, Baek JH, Kim YS, Sung JY, Lim HK, Choi H, et al. Efficacy and safety of ethanol ablation for thyroglossal duct cysts. AJNR Am J Neuroradiol 2011; 32:306-9. doi: 10.3174/ ajnr.A2296.
22. Kim MG, Kim SG, Lee JH, Eun YG, Yeo SG. The therapeutic effect of OK-432 (picibanil) sclerotherapy for benign neck cysts. Laryngoscope 2008; 118:2177-81. doi: 10.1097/MLG. ob013e3181864acf.

23. Ohta N, Fukase S, Suzuki Y, Ishida A, Aoyagi M. Treatments of various otolaryngological cystic diseases by OK-4321: Its indications and limitations. Laryngoscope 2010; 120:2193-6. doi: 10.1002/lary.21141.

24. Shanti RM, Aziz SR. HIV-associated salivary gland disease. Oral Maxillofac Surg Clin North Am 2009; 21:339-43. doi: 10.1016/j.coms.2009.04.002.

25. Monama GM, Tshifularo MI. Intralesional bleomycin injections in the treatment of benign lymphoepithelial cysts of the parotid gland in HIV-positive patients: Case reports. Laryngoscope 2010; 120:243-6. doi: 10.1002/lary.20577. 